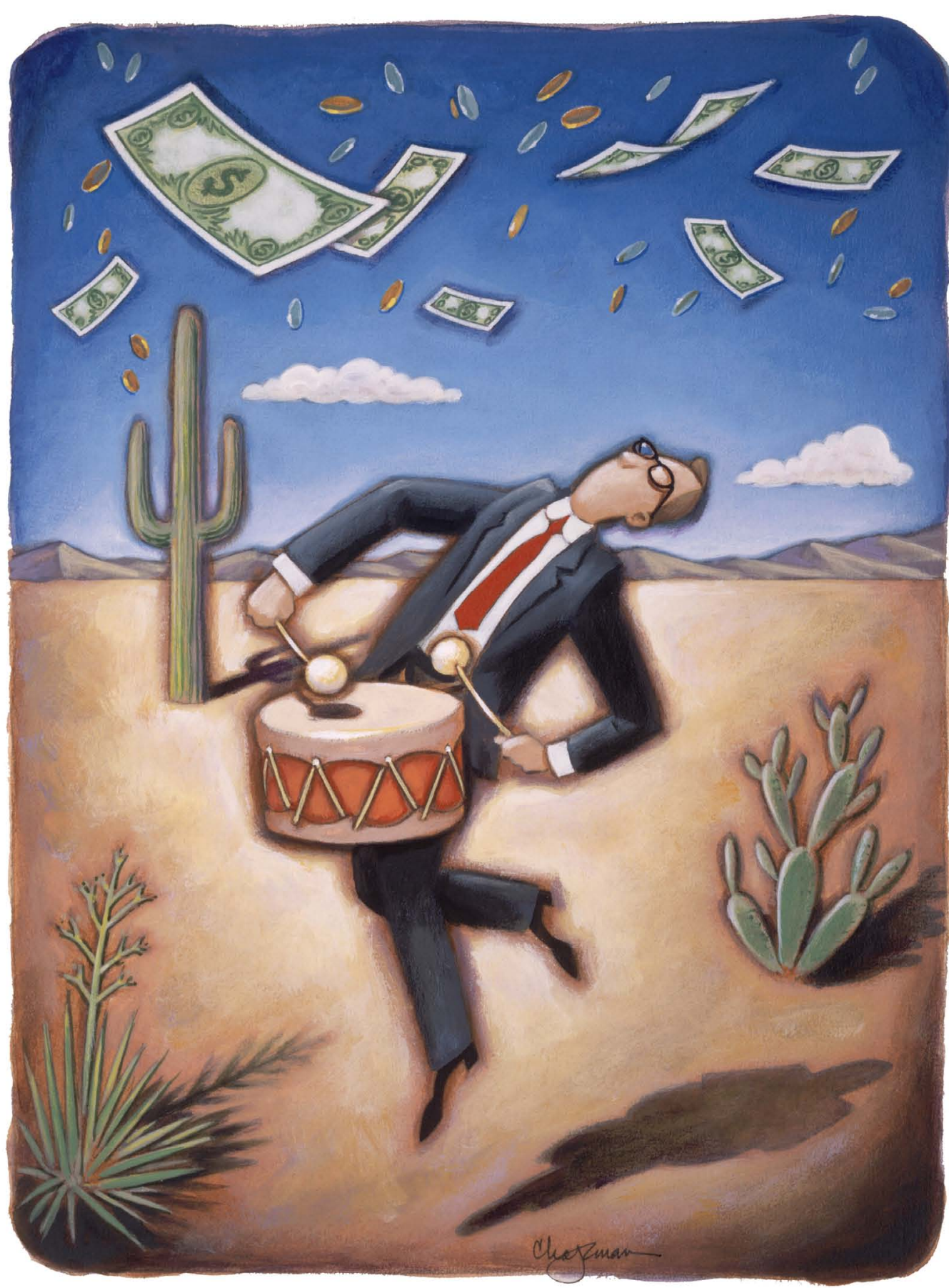

\section{No bailan solos}

Chile es atractivo para los inversionistas extranjeros, pero las ventajas del país no significan un pase libre a la recaudación ilimitada de impuestos. Por Juan Foxley $R^{*}$
Quizás la cuantificación global más rigurosa respecto del clima para la inversión por paises está en el estudio del Banco undial Investment Across Borders, reaIzado este año. Comprende 87 paises identifica aquellos sectores en que se restringe el acceso a inversionistas nobidentes. Además, cuantifica barreras burocraticas, la fuerza del sistema judicia El arbitraje de conflictos.

masto informacion para alimentar las decisiones de inprencia y predictibild Sin mbaro, los atos ayudan también a que los gobiernos, para mantenerse competitivos, ajusten sus incentivos a las mejores prácticas.

Según el estudio, Chile es uno de los pases más abiertos a la inversión extranier en el mundo en 33 sectores analizados. La dificultad que tiene un no-residente para instalarse en el pais es relativamente baja: la tramitacion para iniciar negocios dura 29 dias, que se comparan positivamente Las 42 para el mundo.

Ae su vez, el indice de fuerza de la ley se compara también favorablemente con tel paistraje. El indice para Chile (949) Supera a los promedios de la región (87.5) $y$ del resto del mundo (852) y satisface principios de autonomí como la imparcialidad del árbitro y el alcance de sus fallos (el criterio kompetenz-kompetenz').

En materia tributaria, los contratos de inversión en Chile han estado enmarcados por el Estatuto de Inversion Extranjera (D 000) y tienen estatus de ley de la Republica. con los 74 dias promedio para la región
Las disposiciones del DL 600 están hoy el que el Estado pueda participar en los besometidas a una revisión, a partir de la neficios de mayor precio de los minerales, petición de algunos parlamentarios. Ellos el proyecto reciente acordado entre gobierpoponen establecer un régimen mas fa- no y sectores de la oposición respecto de orable al pais en materia de recaudación solestos. considerar los siguientes aspectos:

El régimen es, en la práctica, una opción quesentrega años en generat, $y$ quince años respecto del impuesto especifico a la gran mineria), pero no fue gratis. El precio pagado por los inversionistas a cambio de invariablilugar del 350\% por ciento para de $42 \%$ en de utilidades. En el caso particular de la gran minería, desde 2005 la invariabilidad se acotó a 12 años, y el precio implicito de dicho compromiso fue cargar un impuesto spectico adicional de $4 \%$ a las uilidades a conóliza de seguro contra alzas de impuesto. Y por esa póliza, los inversionistas han pagado una prima.

Es probable que la estabilidad reflejada en impuestos $\mathrm{y}$ patentes invariables sea un clima de inversión reflejado en los buenos indices de Chile, no hay necesidad de establecer incentivos adicionales. No obstante, es evidente que eliminar la opción de invariabilidad agrega riesgo-pais a las decisiones de inversión extranjera futura. Si lo que un impuesto variable a la minería cumpe bien con tal requisito sin introducir incer-

tidumbre.

Cualquier alteración al DL 600 debería paises receptores de inversion extranjer

que imponen otros paises. Por ejemplo. erien 39 por ciento, carga que subiría hasta unos cuatro puntos con el impuesto variable que está en discusión. En Australia considerando los créditos tributarios por exploración y otros que una reciente mocion legislativa no logro eliminar. Y, sin ir tan lejos, Peru aparece con porcentajes de ser aun menor si se consideran las variadas excepciones de tratamientos caso a caso. Clo a inversión extraniera bien podría varo a la se sion extrancera, bien podrava作 asunto es que todos los paises emergentes compiten de algún modo por acompasarse con el capital externo. Si al contrario, un pais voluntarista optara por recaudar más por el simple expediente de alzar tributos resultado será tasas altas que recauda poco. Es un baile atrevido que puede term invariabil las tributari (ente die $y$ por posibilidas de erminó asi, de paso, con la pérdidas antiguas. En suma, el DL 600 ha periser cuenta la carga tributaria de otros serador del 35 , pero la carga real parece en disonancia con el trato que dan otros, nar bailandose solo. 